DOI 10.37882/2500-3682.2021.11.15

\title{
ГУМАНИЗМ И ГУМАННАЯ ЛИЧНОСТЬ В СОЦИАЛЬНО-ФИЛОСОФСКОМ ДИСКУРСЕ
}

\section{HUMANISM AND HUMANE PERSONALITY IN SOCIO-PHILOSOPHICAL DISCOURSE \\ V. Skopa}

Summary: The article provides a scientific interpretation of the concept of humanism and humane personality in the socio-philosophical discourse. The humanistic interpretation in philosophy does not have a specific disciplinary affiliation, and the split along the line of «humanismantihumanism» passes through various philosophical trends and views. In many ways, the process of forming a humane personality is associated with the process of education, which is based on the ideas of humane pedagogy, has its own characteristics that are sharply different from traditional approaches. A humane person is characterized by the perception of another person as the highest value. The formation of a humane personality in harmony with his inner world and the environment is possible only under conditions of versatile influences, which are provided primarily in the process of humanistic education and moral development.

Keywords: humanism, personality, philosophy, worldview, education.

\author{
Скопа Виталий Александрович \\ Д.и.н., профессор, Алтайский государственный \\ педагогический университет, г. Барнаул \\ sverhtitan@rambler.ru
}

Аннотация: В статье дается научная интерпретация понятию гуманизм и гуманная личность В социально-философском дискурсе. Гуманистическая трактовка в философии не имеет определенной дисциплинарной принадлежности, а раскол по линии «гуманизм-антигуманизм» проходит через различные философские течения и воззрения. Во многом процесс формирования гуманной личности сопряжен с процессом образования, который основанный на идеях гуманной педагогики, имеет свои особенности, резко отличающиеся от традиционных подходов. Гуманная личность характеризуется восприятием другого человека как высшей ценности. Формирование гуманной личности, находящейся в гармонии со своим внутренним миром и окружающей средой, возможно только в условиях разносторонних влияний, которые обеспечиваются прежде всего в процессе гуманистического воспитания и нравственного развития.

Ключевые слова: гуманизм, личность, философия, мировоззрение, образование.

тегориальное обоснование гуманизма, так как не ясно, средствами какой дисциплинарной матрицы или философского направления он может быть адекватно выражен $[11,20]$.

Во многом процесс формирования гуманной личности сопряжен с процессом образования. Данный процесс, основанный на идеях гуманной педагогики, имеет свои особенности, которые резко отличают его от традиционной. Они связаны с психологией ребенка, с его духовно-нравственным становлением, с содержанием образования, дидактической направленностью, оценкой деятельности [2]. Особенность и специфика гуманного образовательного процесса проявляется, прежде всего, в том, что учебные дисциплины называются учебными курсами [15]. Исходя из этого, внимание концентрируется на том, что содержание образования должно включать не только процесс обучения, но еще и формирование духовно-нравственного и познавательного мира учащихся.

Особенности гуманного образовательного процесса порождают такое качество, на основе которого происходит становление личности ученика, расширение его духовного и морального мира. Все качества, развивающиеся в учениках, реализуются через духовный и нрав- 
ственный характер преподавателя [17].

Воспитание личности - проблема, которая привлекала внимание мыслителей, ученых, общественных деятелей на разных этапах исторического развития общества. Так, в эпоху античности - человек рассматривался Аристотелем как высшее благо не в чувственных удовольствиях и материальных благах, а в духовном удовлетворении. В Средневековье - человек в христианской парадигме трактовался двойственно: с одной стороны, он изначально нес на себе печать греха в телесности, с другой - в нем присутствовала божественная частица - душа. Новое временя перевернуло сознание. Эгоцентризм мироощущения делал каждого индивида центром своих интересов и критериев оценок, человек становился объектом познания во всем своем проявлении $[7,12,14,18]$.

В условиях постмодерна данная проблема не потеряла своей актуальности, а наоборот приобрела еще большее значение. Современниками выдвигается вопрос формирования у молодого поколения таких качеств, как порядочность, честность, доброта, патриотизм, достоинство, а также ориентация его на поступки, которые соответствуют высокому уровню духовно-нравственного развития [16]. Как следствие, перед системой образования и воспитания встает важная задача - формирование гуманной личности с высоким уровнем морального, этического и культурного развития, которая способна к самосовершенствованию, эффективному взаимодействию с другими людьми и обществом в целом.

Проблема формирования гуманной личности приобрела довольно обстоятельное освещение в научных источниках. Раскрытию понятия гуманизм, гуманная личность и особенностям ее развития посвящены работы педагогов, философов, психологов. Так, к определению составляющих гуманистической личности и установлению способов ее формирования обращаются И. Бех, А. Власенко, К. Орлов $[6,16]$. Так же данный аспект нашел отражение в трудах Ш. Амонашвили, Е. Бондаревской, А. Лямовой $[2,9,13]$. В тоже время несмотря на довольно основательное освещение сущности гуманной личности и гуманизма, вне поля зрения исследователей остались вопросы, связанные с целостной характеристикой этих феноменов в философском дискурсе, основанной на анализе различных взглядов: педагогов, философов, психологов.

Формирование личности - сложный и многогранный процесс, который происходит под влиянием внешних и внутренних факторов. Так, основываясь на деятельностный подход, многие ученые рассматривают это в узком и широком смысле. В узком смысле - это формирование профессионального мастерства в процессе различных видов деятельности человека. В первую очередь это относится к процессу обучения и воспитания как целост- ным категориям. В широком смысле - формирование гармонично развитой, духовно богатой, довольной жизнью личности, способной достигать высоких творческих результатов в выбранной деятельности $[8,10,13]$. Фактически - это реализация сформированного специалиста. В этом определении внимание фокусируется на временном измерении формирования личности в тесной взаимосвязи с различными факторами и видами деятельности.

Категория личность не имеет однозначной трактовки. Каждый исследователь привносит в раскрытие ее сущности те или иные признаки, элементы. Так, с философской точки зрения личность интерпретируется как «способность человека быть автономным носителем общечеловеческого опыта и исторически выработанных человечеством форм поведения и деятельности» $[3,11$, 20]. В психологическом смысле, «личность» - это системное качество индивида, который вовлечен в социальные связи и формируется в процессе социальной деятельности и общения» $[5,16,19]$. По мнению Т. Лихачева, многообразие взглядов на определение этой категории свидетельствует о том, то личность олицетворяет целостную сложнейшую систему, составляющими которой есть определенные подсистемы, или «сложные целостные системы систем» [12]. Американский психолог Г. Олпорт считает, что понятие личность следует рассматривать как динамическую организацию тех психофизических систем внутри индивида, которые определяют характерные для него поведение и мышление [1].

Обобщая приведенные взгляды, можно констатировать, что личность - это комплекс характеристик человека, который позволяет выделить ее среди других людей, делает ее целостной, уникальной и неповторимой. Относительно понятия «гуманная личность», оно также не имеет однозначного понимания. Например, представители западной философско-педагогической мысли К. Роджерс, А. Маслоу, Э. Фромм, Ж.-П. Сартр, В. Франкл соотносят гуманную личность с такими качествами и свойствами, как ответственность, способность к самоактуализации и этического выбора, готовность отвечать за свои действия $[11,14]$. В более общем смысле гуманная личность - это такая личность, которая:

- признает человека высшей ценностью, характеризуется уникальностью, неповторимостью, своеобразием, автономностью, правом на собственный путь, направляясь которым она раскрывает свои смыслы, как потенциальную возможность жизни;

- развивает свои потенциальные творческие возможности, ориентирована на самоизменение и саморазвитие;

- способна к свободному выбору, что составляет основу ее развития в направлении положительных личностных изменений;

- способна осуществлять конструктивные личност- 
ные изменения для гуманизации межличностных отношений, выстраивать их на основе положительного восприятия другого человека, его активного эмпатического слушания, конгруэнтного самовыражения в общении с ним;

- стремится к гуманизации и гармонизации отношений со своим внутренним аутентичным «Я» [16].

Со способностью к сопереживанию, готовности к свободному гуманистически ориентированному выбору и индивидуальному интеллектуальному усилию, уважением самого себя и других, независимостью во взглядах и открытостью к новым и неожиданным мыслям связывает гуманную личность В. Краевский. Итак, гуманная личность - это личность, которая постоянно развивается, готова к изменениям, во взаимодействии с окружающими, руководствуется исключительно гуманистическими ценностями; ей присуща высшая и ценность других, а также умение делать нравственный выбор и нести за него ответственность.

В работе И. Беха указано, что: «гуманность - это надхарактеристика личности, которая аккумулирует комплекс качеств, характеризующих ценностное отношение человека к человеку, уважение его прав и свобод» [6]. Согласно определению Г. Балла, гуманность - это свойство сознания, чувственной сферы и поведения человека, которая предусматривает хорошее отношение к окружающим, сопереживание другим, содействие их благу при отсутствии причин для другого поведения, а гуманизм акцент на возможности «прогрессивного развития индивидов и сообществ, расширение пространства их свободы» [5].

В педагогической литературе получила признание мысль о том, что гуманность состоит из компонентов, которые воплощают ее содержание. К ним относятся: уважение, справедливость, сострадание, чувственность, самокритичность, мужество, доверие, а также те, которые обеспечивают оптимальную форму ее воплощения: вежливость, терпимость, требовательность, уступчивость и скромность [4].

Гуманность невозможна без чуткого отношения к человеку, без совести, ведь голос совести - это внутренняя потребность действовать таким образом, чтобы приносить пользу людям. Отсюда гуманистическое отношение предполагает проявление заботы, внимания, доброжелательности, уважения, терпимости к другим, независимо от их национальной принадлежности [7]. Итак, гуманная личность характеризуется гуманным отношением к окружающим, восприятием другого человека как высшей ценности, которая имеет право на свободу, удовлетворения своих потребностей на всех уровнях, на физическое и духовное развитие и тому подобное.
Формирование гуманной личности, находящейся в гармонии со своим внутренним миром и окружающей средой, возможно только в условиях разносторонних влияний, которые обеспечиваются прежде всего в процессе гуманистического воспитания и нравственного развития, в первую очередь - ребенка. Поскольку, воспитательный процесс, основанный на принципах гуманизма, направленный на развитие тех качеств, которые являются определяющими для каждой личности, он должен обеспечивать формирование у индивида способности отстаивать собственную жизненную позицию, взгляды и убеждения в различных жизненных коллизиях и проблемных ситуациях. Такие ситуации способствуют обогащению личностного опыта за счет систематического оценивания своих положительных и отрицательных проявлений поведения по отношению к окружающим. Положительные проявления предусматривают установление и развитие взаимоотношений с окружающими на основе гуманистических ценностей, гуманного отношения, которые воплощаются в соответствующих моделях поведения. В научных источниках представлены различные подходы к формированию гуманного отношения: социально-психологический (М. Вейт, И. Иванов), деятельностный (Б. Лихачев, К. Орлов) и целостный (А. Авраменко, А. Востриков, С. Козлова).

С точки зрения социально-психологического подхода, формирование гуманного отношения происходит в условиях коллектива, где в процессе межличностного общения личность познает особенности гуманных отношений и соответствующие им схемы поведения, приобретает практические умения для воплощения собственных гуманистических качеств и ценностей. В основу положено личностное «Я» [16].

В основе деятельностного подхода к формированию гуманного отношения заложена организация коллективной деятельности, в процессе которой создаются условия для оказания помощи другим. В результате активизируется процесс формирования и развития гуманистических чувств к окружающим: доброжелательность, уважение, эмпатия, сочувствие. Привлечение к деятельности способствует формированию у индивида потребности в заботе о других людях, осознанию человека как высшей ценности, активизации мотивации к такому виду деятельности сказывается на поведении индивида в целом [4].

Системный подход предполагает формирование гуманного отношения на основе привлечения к межличностным отношениям, основанных на морали, в которых воплощаются нормы гуманизма. По мнению А. Авраменко, гуманные отношения - это отношения, возникающие в процессе нравственной деятельности, которые базируются на моральных нормах и принципах. 
В свою очередь А. Лямова, считает, что в основу гуманных отношений и его формированию следует относить следующие компоненты:

- рациональный - гуманистическое мировоззрение, знания, убеждения;

- эмоциональный - ценностные ориентации, мотивы, чувства, эмоции;

- деятельностный - навыки нравственного поведения [13].

На наш взгляд, при организации воспитания, направленного на развитие гуманного отношения и поведения в том числе, необходимо учитывать все названные подходы и принципы их реализации.

Анализируя особенности формирования гуманной личности, нельзя обойти вниманием факторы, которые детерминируют ход этого процесса. К таким факторам можно отнести окружающую среду и внутренний мир человека, который постоянно меняется под влиянием накопленного опыта и формировании внутренних ценностей. Последние занимают центральное место, поскольку, как справедливо отмечает А. Серый, ценность является составной частью сознания личности, при этом такой частью, без которой нет и самой личности [19]. Несмотря на это, можно констатировать, что без гуманистических ценностей невозможно существование и гуманной личности. Критериями таких ценностей выступают, теоретические представления о таких нравственных качествах, как доброжелательность, уважение к человеческому достоинству, милосердие, доброта, человечность, толерантность, порядочность, умение прощать, не делать зла, а также практические действия, поступки, мотивы, стимулы и намерения людей, реализуемых с опорой на указанные качества.

Будучи присвоенными, ценности превращаются в ценностные ориентации - элементы структуры сознания личности, характеризующие ее направленность. Именно направленность определяет цели, жизненные планы, степень жизненной активности, объединяет интересы, потребности, духовные и практические наставления, вызывает стиль поведения.

Таким образом на основе анализа научной литературы, можно сделать вывод, что постгуманизация современного образования может внести значительный вклад в философское постижение образовательной практики, а это, в свою очередь, может способствовать значительному расширению мировоззренческих границ философско-образовательного дискурса.

Знания о человеке сочетают свойства науки и мировоззрения и ориентируют подрастающее поколение на развивающее обучение и поиски личностных смыслов, что согласуется с принципом соответствия содержания образования базовой культуре личности и отвечает требованиям гуманистической педагогики. Исходя из этого, гуманная личность характеризуется сложившимся сознанием, мышлением, знаниями и представлениями о гуманизме и особенностями его проявления, а также наличием гуманистического потенциала, устойчивой мотивацией к гуманистической деятельности.

\section{ЛИТЕРАТУРА}

1. Allport G.W. Pattern and Growth in Personality. New York, 1961. - 194 p. c. 158-169.

2. Амонашвили Ш.А. Гуманно-личностный подход к детям. М., 1998. - 544 с.

3. Ананьев Б.Г. Человек как предмет познания. СПб., 2001. - 288 с.

4. Андреев Э.М., Миронов А.В. Социально-гуманитарное знание и образование: новые реалии, иные измерения, информационная безопасность. М., 2001. -142 c.

5. Балл Г.А. Ориентиры современного гуманизма (в общественной, образовательной, психологической сферах). Житомир, 2008. - 232 с.

6. Бех И.Д. Концепция воспитания гуманистических ценностей учащихся. К факультативному курсу «0сновы гуманистической морали» // Школьный мир. 2005. № 45. С. 4-11.

7. Блюмкин В.А. Нравственное воспитание: философско-этические основы. Воронеж, 1990. - 195 с.

8. Божович Л.И. Избранные психологические труды. М., 1995. - 479 с.

9. Бондаревская Е.В. Воспитание как возрождение гражданина, человека культуры и нравственности. Ростов н/Д, 1993. - 34 с.

10. Долженко 0. Университет в условиях межцивилизационного зазора // Alma Mater: Вестник высшей школы. 2007. № 2. - C. 20-26.

11. Лекторский В.А. Идеалы и реальность гуманизма // Вопросы философии. 1994. № 6. - С. $22-28$.

12. Лихачев Т.Б. Введение в теорию и историю воспитательных ценностей. Самара, 1997. - 84 с.

13. Лямова А.А. Проблема воспитание гуманного отношения к человеку у студентов медицинского вуза // Pedagogical sciences fundamental research: сб. наук. трудов. 2011. № 8. - С. 36-40.

14. Момджян К.Х. Введение в социальную философию: учеб. пособие. М., 1997. - 448 с.

15. Момджян К.Х. Социальная философия // Новая философская энциклопедия: В 4 т. М., 2010. Т. 1. - С. 609-611.

16. Орлов К.А. Особенности формирования гуманности на отдельных этапах развития личности // Совершенствования учебно-воспитательного процесса в образовательном учреждении: сб. науч. трудов. М., 2007. - С. 162-165. 
17. Печчеи А. Человеческие качества. М., 1980. - 312 с.

18. Пигров К.С. Социальная философия: учебник. СПб., 2005. - 296 с.

19. Серый А.В. Психологические механизмы функционирования системы личностных смыслов. Кемерово, 2002. - 186 с.

20. Тюгашев Е.А. Феномен философии: рефлексия дискурса. Новосибирск, 2008. - 413 с.

( С Скопа Виталий Александрович (sverhtitan@rambler.ru).

Журнал «Современная наука: актуальные проблемы теории и практики»

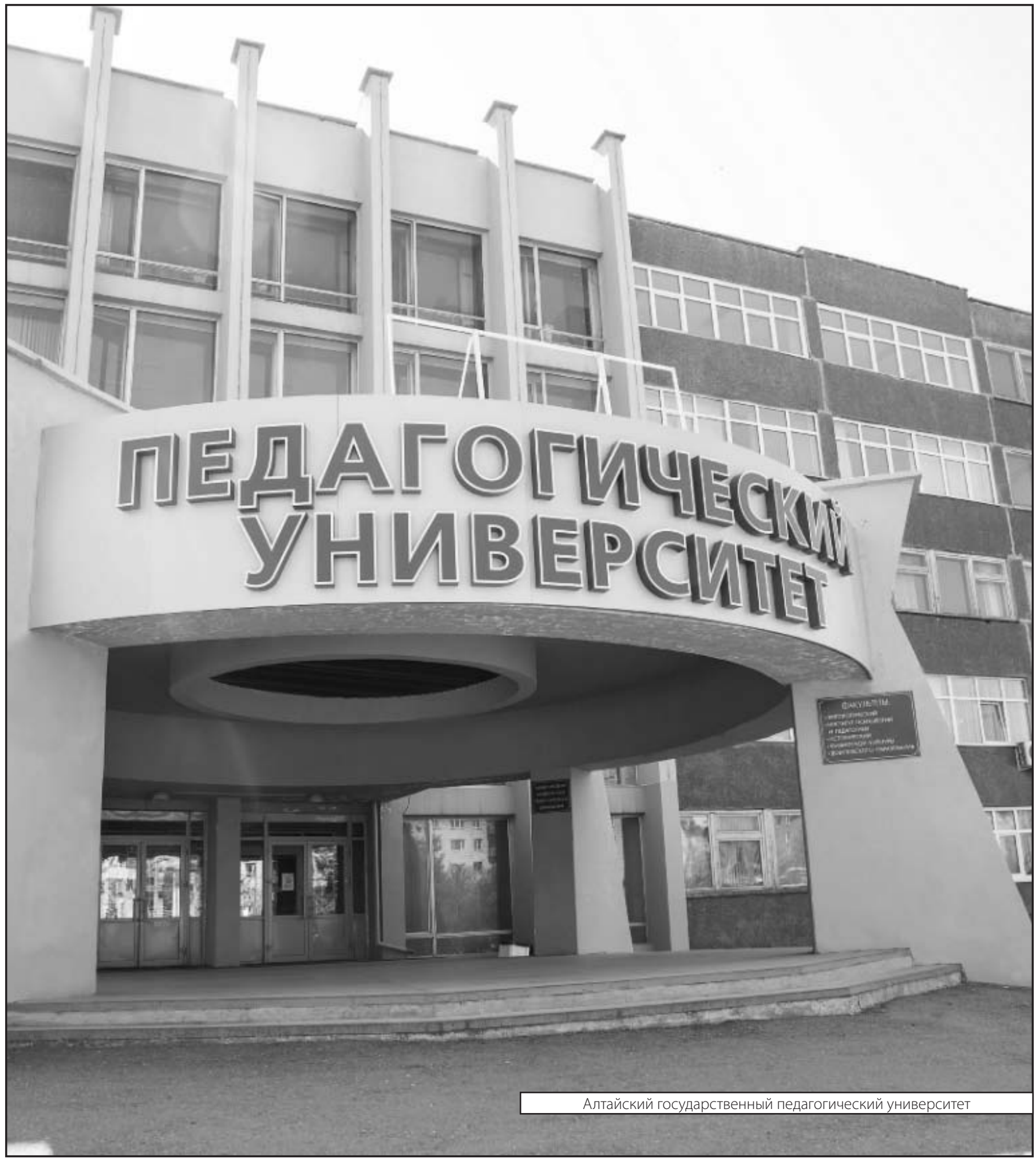

